\title{
Sustainability of United Nations Recruitment: An Empirical Analysis of Recent Vacancy Advertisements of United Nations Specialized Agencies
}

\author{
Dr. Suyu Liu ${ }^{1}$
}

\begin{abstract}
This paper examines the sustainability of recruitment in the United Nations (UN), the largest global inter-governmental organization working on sustainable development. It investigates the sustainability of UN recruitment on three main dimensions: remuneration and job stability; meritocracy and fairness; cost and efficiency, with the data from recent vacancy advertisements of two UN specialized agencies. The analytical results suggest that being different from the existing knowledge of UN recruitment, the job stability in UN as shown by the data is higher due to the large proportion of staff vacancies and long-term job contracts. The remunerations to UN job incumbents are high, not only because of the widely-known attractive packages which are provided referring to the highest remuneration levels of national civil service, but also due to the subsidies of working in hardship places. Also, it is found that UN specialized agencies have developed detailed competency frameworks for recruitment to ensure the meritocracy. However, due to the essential monitoring procedures, UN recruitment is often lengthy and costly. Therefore, in the dilemma of meritocracy, fairness, and efficiency in recruitment, efficiency is not highly emphasized in UN recruitment practice, in comparison with meritocracy and fairness. Practical recommendations for improving sustainability of UN recruitment are provided, but more evidence and implications are to be provided by future research.
\end{abstract}

Key Words: United Nations; Recruitment; Sustainability; Meritocracy; Efficiency

\section{Introduction}

The sustainability of recruiting workforce receives an increasing attention from scholars and practitioners, as it is directly related to staff morale, and the sustainability of employers and their businesses (e.g., Wolcott et al 2008). This also applies to the United Nations (UN), the largest inter-governmental organization in the world, which works on the sustainable development of the world (e.g., Terzi and Fall 2014).

The recruitment in UN and its specialized agencies (sometimes also informally termed as 'UN organizations') includes two major types: non-staff recruitment and staff recruitment. For non-staff recruitment, although there is no formal definition in UN, in practice it is usually operationalized as recruiting individuals to work for specific UN assignments with relatively short periods. Non-staff personnel are usually bound by their recruitment contracts rather than the formal UN staff rules. Similarly, they are not officially considered as UN employees and thus usually not entitled to privileges enjoyed by UN staff members. In contrast, UN staff members are recruited as international civil servants and are therefore entitled to relevant privileges. Also they undertake the responsibility to abide by the rules as formally outlined in the Staff Regulations and Rules of the United Nations (UN 2018). UN staff members usually hold longer employment contracts and better remuneration

${ }^{1}$ Department of Policy Research and Statistics, United Nations Industrial Development Organization. Vienna, Austria. 
packages than non-staff personnel. The staff personnel are classified into two sub categories: local staff members who are recruited from the country where the recruiting UN agencies are located, and international staff members who are recruited globally. In practice, local staff members are usually either nationals or legal residents of the hosting countries of the recruiting UN agencies. They may be occasionally recruited non-locally if qualified candidates cannot be found in the local areas. By the end of 2012, UN has a workforce of 83,319 staff personnel including 35,897 female staff members, which is about $43.1 \%$ of the staff personnel (UN System Chief Executives Board for Coordination 2013, p1-3). Based on questionnaires and existing practice, Terzi and Fall (2014, p67) estimate that by the end of March 2013, UN has 87,199 non-staff personnel, which is more than the number of staff personnel. The estimated total workforce in UN is thus slightly over 170,000 based on the above two figures.

$\mathrm{UN}$ as an employer is by nature international, multi-lingual, and diverse in terms of geographic and gender representativeness. To promote the sustainability of its workforce recruitment, UN emphasizes meritocracy and diversity. For example, the UN Charter outlines that 'the paramount consideration in the employment of the staff and in the determination of the conditions of service shall be the necessity of securing the highest standards of efficiency, competence, and integrity. Due regard shall be paid to the importance of recruiting the staff on as wide a geographical basis as possible' (UN, 1945, article 101).

This paper aims to provide empirical evidence to develop a more comprehensive understanding of UN recruitment, especially its sustainability. In this paper, sustainability of UN recruitment is defined as the extent to which UN can recruit suitable talents in a fair and meritocratic way, with reasonable recruitment cost. In particular, this paper explores the possible balances of meritocracy, diversity, and efficiency of UN recruitment, which may also enrich academic knowledge in similar areas. It also aims to examine possible factors which may affect the sustainability of UN recruitment. Existing views on the sustainability of UN recruitment vary, which also lead to different understandings of factors related to sustainability of UN recruitment. Therefore, the next section reviews the existing literature of UN recruitment and analysis of its sustainability.

\section{Literature review}

Previous research on UN recruitment is relatively scarce due to the lack of knowledge of the UN system and its operations. In comparison with national and crossnational employers, the inter-governmental nature of UN attracts discussions about its recruitment in three main aspects: (1) remuneration and stability; (2) efficiency and cost; (3) meritocracy and diversity.

\subsection{Remuneration and stability of UN jobs}

The remuneration for working in UN refers to the highest paying national civil service to maintain its competitiveness. The actual packages may be subject to readjustment according to different working locations to reduce regional disparities in UN remunerations. The competitive remuneration packages are widely believed as factors which attract talents to work in the UN and increase the sustainability of UN recruitment. However, scholars also have different views regarding this point. For example, Vaubel et 
al (2007) use a principle-agent model and argue that as an agent of member states, international organizations including UN may have incentives to increase resource input from member states, such as the number and cost of staff. This is a possible reason for some member states to consider that the UN remuneration is excessive. Beigbeder (1980) argues that it is difficult to accurately compare the UN salary scales with national civil service remunerations, as the calculation may differ significantly from country to country and could be affected by a number of factors such as exchange rates. Remuneration issues have caused some disputes between UN workforce and UN agencies over the past few decades, which undermines the sustainability of UN recruitment as it may have caused a '...graduate erosion of the international civil service' (Beigbeder 1980, p149).

The internal remuneration disparities between staff and non-staff personnel in UN are also noted and considered as a factor which jeopardizes the sustainability of UN recruitment. For example, Terzi and Fall (2014) find that UN agencies have strong financial incentives to recruit a high proportion of non-staff personnel as non-staff personnel usually cost less than staff members, even sometimes non-staff personnel are actually in de facto employment. This may lead to high turnover and the lack of stable and motivated workforce, even though the non-staff members are remunerated in line with the highest local standard.

Job stability is also a concern about UN recruitment. The number of permanent jobs is reducing. Also a large sum of such positions were filled long time ago and not recently. Current UN recruitments of staff personnel are more likely to be fixed term contracts shorter than five years (sometimes with possibility to renew) and temporary appointments which are less than 1 year (without high expectation of renewal or conversion into other appointments). This may have negative impact on staff inclusion and cohesiveness (Stoddart 2007). For non-staff workforce in UN, this has become a widely known challenge to the sustainability of UN recruitment, as non-staff contracts are usually short term and subject to frequent renews (Terzi and Fall 2014).

\subsection{Efficiency and cost of UN recruitment}

While UN aims to recruit talents with highest standards of competence, fairness and integrity, the efficiency in recruitment is unlikely to be maintained, and the recruitment cost is expectedly to be high. This is firstly because in order to keep a fair recruitment process, it is necessary to establish rather sophisticated and complicated monitoring procedures which may be relatively lengthy (Bulkeley 1990). Such complicated and lengthy recruitment process also increases the UN recruitment cost and reduces the sustainability of UN recruitment. For example, Kretchik (2003) finds that it takes around 4 months to establish a UN operational force and find suitable trainers to deliver training to the newly formed operational force. In fact, this is a dilemma in UN recruitment, as it is difficult to establish perfect procedure which can maximize the fairness and outcomes of recruitments, while minimizing the recruitment costs and inefficiency. An often-used mode of UN recruitment in face of this dilemma is to select candidates based on recommendations from national governments of member states. However, this often 
causes the problem of meritocracy and diversity, which is another dilemma that will be examined in the next sub-section.

\subsection{Meritocracy and diversity in UN recruitment}

Bulkeley (1990) finds that UN organizations may have very limited contact with recruiting services at national level, and therefore they rely on their working contacts with government bodies to identify and select suitable candidates for job vacancies. This echoes to Haynes (2008), who argues that although the system to intake UN employees directly 'on loan' from national governments has been largely abolished, UN recruitment still often relies on governments to provide suitable applicants.

Strong reliance on national governments to provide or recommend candidates put the neutrality and meritocracy of UN recruitment in doubt, which negatively affects the sustainability of UN recruitment. For example, Haynes (2008) demonstrates the interaction between Cold War politics and UN recruitment and staffing practices. Bulkeley (1990) also finds that member states have influences on UN recruitment. For example, the former Soviet Union has a tradition of avoiding direct UN recruitment of its nationals. Instead candidates are often proposed by the government to work in UN for limited periods. Such practices become challenges for maintaining meritocracy and diversity in UN recruitment, as candidates recommended by national governments may not necessarily have the highest competence as international civil servants for the whole world.

The emphasis on both meritocracy and geographic diversity in the UN recruitment itself also creates a dilemma: how about the situation if candidates with highest competences are disproportionally from certain regions and/or countries? Even if the possible influence from member states on UN recruitment were excluded, this is still a possible situation in practice due to the sharp disparities in socioeconomic development across regions and/or countries. For example, nationals of developed countries usually have higher educational levels than developing countries and therefore would have more advantages when applying for UN jobs, which often have high and strict requirements on education qualifications. This is a possible reason why the geographic distribution of staff is imbalanced (World Health Organization 1976), and nationals of some member states are under-represented in UN. Swift (1957, p233) provides an example which perfectly explains the situation: '...the Secretary-General has been unable to find a sufficient number of qualified candidates in the underrepresented countries for existing posts as junior statisticians and junior librarians. In some cases, as with some statistical posts, the Secretary-General had either to leave the posts vacant or fill them from the AngloSaxon countries where qualified candidates were readily available'. Similarly, Stiglitz (2000) argues that in International Monetary Fund's (a specialized agency of the UN) recruitment of economists, although it pays attention to talents from developing countries, its staff members still dominantly consists of economists from top universities, which are mainly located in developed countries.

The existing studies of UN recruitment, especially on its sustainability, though relatively scarce, have provided readers with a rough understanding of the UN system and its recruitment principles and practices. They presented macro perspectives of UN recruitment by outlining the historical developments of UN recruitment at different eras (especially at early eras). However, there are still significant limitations. Firstly, the dilemma of meritocracy, fairness, and efficiency of UN recruitment has not been fully examined. 
Secondly, analysis of UN recruitment based on micro-level empirical evidence is not sufficient in previous studies. Therefore, this paper aims to use micro-level data to further analyze the sustainability of UN recruitment.

\section{Data and methodology}

This paper reviews all the published job advertisements by World Health Organization (WHO), a UN specialized agency in health, headquarter in Geneva, Switzerland, between 30 January 2020 and 26 February 2020, by selecting 'last 28 days' under the 'Posting Date' menu (accessed on 26 February 2020). All these job advertisements are published online at WHO's career website (external candidate access). This is a public-accessible website where jobs for internal candidates only or not advertised are not shown. This search obtained 91 job advertisements.

This paper also explores all the published job advertisements by United Nations Educational Scientific and Cultural Organization (UNESCO), a UN specialized agency in education, science and culture, headquarter in Paris, France, with the closing date between 27 February 2020 and 19 April 2020 (accessed on 27 February 2020). Unfortunately the job posting dates are not available on UNESCO career website, but according to the common practice of UN agencies, an external job should be advertised no less than 15 days, it is therefore possible to infer that these job advertisements were advertised on or before 12 February 2020. Similar to WHO, these job advertisements were accessible online by all internet users. Vacancies for internal applicants only and/or not advertised are not shown on this website. This search collected 52 job advertisements.

The selection of WHO and UNESCO as sample for this paper is because of their locations, specialization, and size of workforce and recruitment. Health and education are among most important issues of global development and are therefore also included in UN Sustainable Development Goals (SDGs). WHO and UNESCO have 192 and 193 member states respectively, which demonstrate a wide representativeness and geographical coverage. It is an important reason to choose WHO and UNESCO for this case study, because eligible candidates of UN agencies must be the nationals of the member states of these agencies. In terms of workforce, WHO employs around 7,000 staff personnel in its headquarter and near 150 country offices, while UNESCO employs around 2,200 staff personnel in its headquarter and over 50 field offices ${ }^{1}$, which are neither extremely large nor too small for analysis. In terms of locations, Geneva is a main home of UN organizations in Europe and a center of UN activities focusing on Europe and Central Asia. Paris is a cluster hosting various UN and other international organizations. Both Geneva and Paris are located in French-speaking regions and therefore bi-lingual working becomes a common practice at WHO and UNESCO, which corresponds to the multilingual nature of UN work.

All the 143 job advertisements of the two UN specialized agencies have information on the job locations, length of job contracts (including possibility of extension or renewal),

1 According to updates on WHO and UNESCO career websites, both double-checked on 7 May 2020. See https://www.who.int/careers/en/ and https://careers.unesco.org/content/Working-atUNESCO-/?locale $=$ en US 
personnel categories (staff or non-staff), and recruitment modes (local or international recruitment). This information, as discussed in previous sections, constitutes factors which may affect the UN recruitment sustainability. In addition, candidates from unrepresentative and/or under-representative member states are particularly encouraged to apply for these jobs ${ }^{2}$. To better understand the job advertisements and recruitment practices of WHO and UNESCO, the detailed competency frameworks of WHO and UNESCO recruitment are also reviewed.

Considering the nature of data and the research aims, the methodology of this paper is explorative and descriptive. However, a number of re-adjustments and classifications of data are conducted. For job location, this paper uses the hardship allowance eligibility to classify whether they are in hardship working areas (International Civil Service Commission, January 2020)3 ${ }^{3}$. For the length of job contracts, this paper puts them into three categories: less than 6 months, 6 to 12 months, and more than 12 months, which are widely selected categories when measuring job securities. For jobs with contractual length of exact 12 months (1 year) but with clear indication of the possibility of renewal exists (even subject to funding, performance and/or other factors), they are classified as 'more than 12 months'. For jobs without clear contractual length (only exist for a few non-staff vacancies), they are all classified as 'less than 6 months', because these jobs are usually for short term assignments. Personnel categories and recruitment modes are usually clearly shown in the advertisements, and if not shown, it is not difficult to infer according to the job titles and levels. For example, job titles such as 'consultant' are usually for non-staff vacancies, 'professional' level and 'director' level vacancies are usually internationally recruited while jobs at 'general service' level and/or for 'national officers' are usually recruited from the country where the posts are located ${ }^{4}$. A few job advertisements in the cohort are not written in English and therefore the paper uses software to translate their actual contents into English ${ }^{5}$.

2 This is a standard practice of UN recruitment. According to WHO (2014), un-representative and under-representative member states included the following (by 2014): Andorra, Antigua and Barbuda, Austria, Barbados, Bahamas, Brazil, Brunei Darussalam, China, Cook Islands, Cyprus, Greece, Grenada, Haiti, Israel, Japan, Kiribati, Kuwait, Kyrgyzstan, Lao People's Democratic Republic, Luxembourg, Marshall Islands, Mexico, Micronesia (Federated States of), Monaco, Montenegro, Nauru, Niue, Oman, Norway, Palau, Paraguay, Poland, Portugal, Puerto Rico, Qatar, Republic of Korea, Russian Federation, San Marino, Saint Kitts and Nevis, Saint Lucia, Saint Vincent and the Grenadines, Samoa, Saudi Arabia, Slovakia, Singapore, Tokelau, Turkey, Tuvalu, United Arab Emirates, United States of America, and Vanuatu.

${ }^{3}$ It is interesting to notice that this classification is not necessarily in line with World Bank's classification of countries by income. Some work locations in lower middle income countries (such as Rabat in Morocco) and even low income countries (such as Kigali in Rwanda) are not classified as hardship work locations. This is possibly because these locations are usually the capital and/or most developed cities in lower middle income and/or even low income countries.

4 Since WHO and UNESCO are headquartered in European Economic Area and European Union, the 'Freedom of Movement' applies. Therefore, in practice, nationals or legal residents of other countries of European Economic Area and/or European Union may also be eligible to apply for local recruitment jobs in WHO and UNESCO headquarters.

${ }^{5}$ In this cohort, these non-English job advertisements are written in French, Spanish, or Portuguese. The main possible reason of these non-English job advertisements is that these languages will be the main working languages in the job locations and thus become essential language skills for the job applicants. These non-English job advertisements can also function as 'informal reading tests' of these languages. 
The selection of the specific period of job advertisements is to minimize the possible disturbances of UN recruitment by the 'holiday periods' (usually mid-December to midJanuary and early July to late August) when many UN workers are on leave and 'conferences seasons' (usually mid-April to mid-June and early October to early December) when large conferences, assemblies, and high level executive meetings often take place. These job advertisements are also recent, which is useful to capture the most updated UN recruitment practice.

\section{Results and analysis}

The descriptive summary of results is presented in Table 1. It shows that 94 of $143(65.7 \%)$ recent job advertisements are for staff vacancies. This proportion is significantly higher than the estimated data for the whole UN system as shown Section 2, which is only less than $50 \%$. The relatively high proportion of staff positions could contribute to the sustainability of UN recruitment, as existing literature has demonstrated that staff positions are usually better remunerated and have stronger job security than nonstaff position. It is also because that a relatively low proportion of non-staff workforce may reduce turnover and promote the morale of employees (Terzi and Fall 2014).

Table 1 Recent job advertisements at WHO and UNESCO

\begin{tabular}{|l|l|l|l|l|l|l|l|l|l|}
\hline $\begin{array}{l}\text { Personnel } \\
\text { categories }\end{array}$ & \multicolumn{3}{l|l}{ Recruitment modes } & \multicolumn{3}{l|}{ Job locations } & \multicolumn{2}{l|}{$\begin{array}{l}\text { Contracts length } \\
\text { (months) }\end{array}$} & Total \\
\hline Staff & $\begin{array}{l}\text { Non- } \\
\text { staff }\end{array}$ & $\begin{array}{l}\text { Local } \\
\text { hire }\end{array}$ & $\begin{array}{l}\text { International } \\
\text { recruitment }\end{array}$ & $\begin{array}{l}\text { Hardship } \\
\text { locations }\end{array}$ & $\begin{array}{l}\text { Other } \\
\text { locations }\end{array}$ & $<6$ & $6-12$ & $12+$ & \\
\hline 94 & 49 & 44 & 99 & 54 & 89 & 25 & 47 & 71 & 143 \\
\hline
\end{tabular}

(Data source: WHO and UNESCO career websites, accessed on 26 and 27 February 2020 respectively)

It is also observed that 99 of $143(69.2 \%)$ of vacancies are advertised for international recruitment. This relatively high percentage helps maintain the meritocracy of UN recruitment, as in comparison with local recruitment, international recruitment usually have higher possibility to attract most qualified talents based on their competence without restrictions on nationality and residential status. Also, comparing with international recruitment, local recruitment is more likely to be influenced by (specific) member states, as the pool of candidates are more restricted.

Table 1 shows that 54 of 143 (37.7\%) recent jobs advertised by WHO and UNESCO are located in hardship work locations. This could have negative impact on the sustainability of recruitment, as working in hardship locations may reduce the incentives of submitting applications from potential candidates with suitable competencies, which could even lead to shortage of suitable candidates and employees (Nungu 2011). However, this may not be the situation for UN recruitment, as working at hardship locations will gain extra allowance for position holders if they are staff personnel. The actual number of allowances varies according to the level of staff members and the difficulty of working and living conditions. Although such remuneration may not be highly attractive to candidates from high income countries (Bulkeley 1990), they are often attractive enough for applicants from lower middle income countries and low income countries. 
In addition, working at hardship locations could be an advantage for future career development, especially within the UN system. It is often considered that having working experience at hardship locations is an asset for applicants, as reducing living and working hardship is also part of UN SDGs. Some UN positions even explicitly require eligible candidates to have working experience at hardship locations and/or an understanding of the hardship context.

Table 1 and Figure 1 show the distribution of advertised vacancies with different contractual lengths. 71 of 143 advertisements are for vacancies with longer than 1 year contractual length, which is narrowly below $50 \%$. Around one third of advertised vacancies (47 of 143) last between 6 and 12 months. Only about 17\% of advertised jobs (25 of 143) are for less than 6 months. In consideration of that UN specialized agencies including WHO and UNESCO have a substantial number of short-term projects, urgent assignments, and temporary work, such distribution of jobs with various contractual lengths should be considered as reasonable and may not have significant negative impact on the sustainability of recruitment.

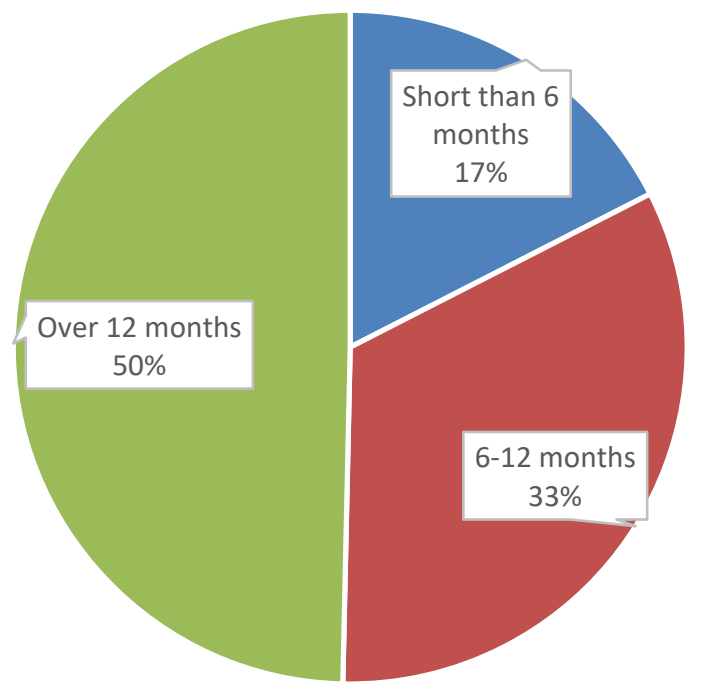

Figure 1 Share of different lengths of job contracts

(Data source: WHO and UNESCO career websites, accessed on 26 and 27 February 2020 respectively)

A review of the recruitment process at WHO and UNESCO as well as their official documents of competency structures enables the paper to further address the dilemma between meritocracy (candidates' competencies), the fairness of recruitment process (including diversity), and the cost or efficiency of recruitment. On WHO career website, it presents a document named WHO Global Competency Model which applies to all the posts. On UNESCO career website, a document titled UNESCO Competency Framework outlines the common values and standards of behavior which should be 
implemented during the recruitment process. It specifically introduces that 'interview panels will include questions around competencies, enabling evaluation of candidates against common, specific indicators' (UNESCO 2015, third page from introduction).

Both documents of competency structures introduce a number of core competencies that should be assessed in the recruitment process. The recruitment decisions should also be made based on the assessments of these competencies. These competencies include but not limited to technical expertise, commitment to work, teamwork, communication skills, result-driven attitude, managing of changes, and respecting for diversity. This gives an indication that in the UN recruitment especially these two organizations, meritocracy (candidates' competencies) is strongly emphasized. This is particularly the situation as both of these organization emphasize that job applications are assessed based on the required competencies.

Fairness of recruitment process is also maintained although not outlined in the competency documents. In the UNESCO advertisements of vacancies, it is clearly stated that nationals from non-representative and/or under-representative countries are equally encouraged to submit applications, and workforce diversity in terms of nationality, culture and gender is respected. In the WHO job advertisements, the organizational commitment to workforce diversity is also explicitly stated. Further to UNESCO's statement, WHO particularly encourages female candidates, as well as nationals from un-representative and/or under-representative member states to submit applications. Both organizations do not charge any fee during the whole application process so that candidates' financial situations will not have direct influence on the recruitment process, which also contributes to the fairness of recruitment process.

However, the other part of the dilemma, which is the cost and efficiency of the UN recruitment, is not strongly emphasized. In an inspection report of recruitment practices in UN including WHO and UNESCO, Fall and Zhang (2012) finds that the UN recruitment is complex and may take a long time, while the managerial attention to recruitment length is insufficient. Although there are targets for recruitment time and UN organizations, these targets vary and the monitoring results show that there are still significant gaps between targets and actual results (Fall and Zhang 2012). This echoes to the findings of Vaubel et al (2007), which argues that as an agent of member states, international organizations including UN do not have sufficient incentives to restrict the quantity of inputs and match them with the size of tasks. On the career webpage of WHO, it clearly states that WHO recruitment process may include different stages such as screening application materials, written test, and interviews, of which the estimated total length would be several months. UNESCO recruitment process looks simpler, but it may still require an assessment exercise and a competency-based interview after shortlisting qualified candidates. To the best knowledge, the exact cost on UN recruitment including WHO and UNESCO recruitment is not publicly available, but it could be a substantial sum. This is because it includes both direct cost such as possible reimbursement of applicants' participation to interviews and expenses to develop and/or purchase written test questions, and also indirect cost such as extra staff stints used in the recruitment process. The high cost and low efficiency of UN recruitment could have negative impacts on the sustainability of UN recruitment. 


\section{Discussion and conclusion}

This paper uses micro-level empirical evidence to analyze the sustainability of UN recruitment, from three main dimensions: remuneration and job stability; efficiency and cost; meritocracy and diversity. Being different from existing literature, evidence from recent vacancy advertisements of WHO and UNESCO shows that the job stability in UN is not as weak as widely believed, because the proportions of long term contracts and staff member vacancies are reasonably high (comparing with short term contracts and non-staff vacancies). Also, the remunerations for UN job holders are competitive. This is because they are provided in reference to the highest level of national civil services, as shown in previous literature. The remunerations may also include hardship allowance if the jobs are located in hardship work areas (over $1 / 3$ in the data). These are factors which contribute to the sustainability of $\mathrm{UN}$ recruitment.

In terms of the dilemma of meritocracy, fairness, cost and efficiency in recruitment, UN organizations especially WHO and UNESCO put more emphasis on meritocracy and fairness. For example, both WHO and UNESCO have established competency frameworks for recruitment in order to select applicants based on their competencies in a number of dimensions. Procedures also exist to ensure the fairness and meritocracy of the recruitment process. However, these increase the cost and reduce the efficiency of UN recruitment. For example, WHO officially states the recruitment process could take months, and existing studies show that there are significant gaps between the targeted and actual lengths of recruitment in UN agencies. It is therefore suggested that researchers and practitioners could investigate more on the reasons of such gaps, and provide practical recommendations to improve the efficiency of $\mathrm{UN}$ recruitment. This paper suggests using more standardized written questions/tests at initial stages of screening applicants, as the fairness and rigidity of standardized written tests have been widely demonstrated (e.g., McCoubrie 2004), and the relatively low cost and high efficiency of these tests are easily perceived.

This paper is not without limitations. The use of published data leads to possible weakness of analysis, for example, the information and explanation behind numbers are usually not available. The existence of comprehensive and detailed competency frameworks in WHO and UNESCO's recruitment is noted, but this paper is unable to explore whether and to what extent the competency frameworks are strictly followed in practice. Future research could conduct interviews to explore the implementation of these competency frameworks in UN recruitment. More practical recommendations for improving the sustainability of UN recruitment could also be generated in future with more empirical evidence and analysis.

Acknowledge: the author appreciates insights from former colleagues at UNESCO and United Nations Industrial Development Organization (UNIDO). However, the views expressed in this paper does not reflect any official stance of United Nations and any of its departments or specialized agencies including UNESCO and UNIDO, unless otherwise specified. 


\section{References}

Beigbeder, Y. (1980). Current Staff Problems in UN Secretariats. International Review of Administrative Sciences, 46(2), 149-159.

Bulkeley, J. (1990). Depoliticizing United Nations recruitment: Establishing genuinely international civil service. New York University Journal of International Law and Politics, 22(4), 749-792.

Fall, P.L. and Zhang, Y. (2012). Staff recruitment in United Nations system organizations : a comparative analysis and benchmarking framework- The recruitment process. United Nations Publications, JIU/NOTE/2012/2.

Haynes, D.F. (2008). Ethics of International Civil Service: A Reflection on How the Care of United Nations Staff Impacts the Ability to Fulfill Their Role in Harmonizing the World. Hamline Journal of Public Law \& Policy, 30(1), 175-222.

International Civil Service Commission (2020). Hardship classification Consolidated list of entitlements circular. United Nations publications, ICSC/CIRC/HC/25.

Kretchik, W.E. (2004). Concerning Multinational Staff Efficiency and Future NATO Operations. Connections, 3(4), 53-58.

Kretchik, W.E. (2003). UN peace operation staff effectiveness. Armed Forces \& Society, 29(3), 393-413.

McCoubrie, P. (2004). Improving the fairness of multiple-choice questions: A literature review. Medical Teacher, 26(8), 709-712.

Meron, T. (1976). Staff of the United Nations Secretariat: Problems and Directions. The American Journal of International Law, 70(4), 659-693

Nungu, J.M. (2011). Policy From Below: Foregrounding Teacher Experiences of Hardship in Remote Rural Secondary Schools in Kenya. Doctor of Philosophy thesis, University of Alberta, Canada.

Stoddart, L. (2007). Organizational Culture and Knowledge Sharing at the United Nations: Using an Intranet to Create a Sense of Community Knowledge and Process Management, 14(3), 182-189.

Swift, R.M. (1957). Personnel Problems and the United Nations Secretariat. International Organizations, 11(2), 228-247

Stiglitz, J. (2000) What I Learned at the World Economic Crisis. The New Republic 17 April 2000 Terzi, C. and Fall, P.L. (2014). Joint Inspection Unit: Use of non-staff personnel and related contractual modalities in the United Nations system organizations. United Nations publication JIU/REP/2014/8.

United Nations Educational Scientific and Cultural Organization (2015). UNESCO Competency Framework. UNESCO, Paris, France

UN System Chief Executives Board for Coordination (2013). Personnel statistics. United Nations publications, CEB/2013/HLCM/HR/12

Vaubel, R., Dreher, A., and Soylu, U. (2007). Staff growth in international organizations: A principal-agent problem? An empirical analysis. Public Choice, 133(3-4), 275-295.

Wolcott, I., Ingwersen, D., Weston, M., and Tzaros, C. (2008). Sustainability of a long-term volunteer-based bird monitoring program : recruitment, retention and attrition. Australian Journal on Volunteering, 13(1), 48-53.

World Health Organization (1976).Recruitment of international staff in WHO. Executive Board 57th Session, EB57/conf.Doc.No.34

World Health Organization (2014). Human resources: annual report. Sixty-seventh World Health Assembly Provisional agenda item 22.1, A67/47 